\title{
Endoscopic Resection Indicated for Double-Pedunculated Esophageal Lipoma
}

A very rare case of esophageal lipoma in the form of two polyps was found during a standard endoscopy in an asymptomatic 63year-old man. On detailed examination, the polyps were seen to originate from a common stalk and pedunculate downward. They were covered with normal esophageal epithelium. Since open surgery seemed too invasive in a patient with so few polyps, and the size of the polyp stalk was considered to be controllable in case of accidental bleeding, we attempted an endoscopic resection. The stalk of the polyp was located at the entry of the esophagus, and peristaltic movement interrupted the delicate operation of carrying out snare cautery of both polyps. Snare cautery was carried out in one polyp, and the other one was resected by coagulation at the stalk (Figure 1). The pathological examination revealed an esophageal lipoma, which did not stain positive to $\mathrm{p} 53$, and did not show any oncogenicity.

Lipomas are very rarely found in the esophagus, and this location includes only $0.4 \%$ of lipomas found in the alimentary tract (1). They are mostly encountered in the cervical area, and this is attributable to its narrowness, with redundant mucosa and loose subcutaneous tissue subject to propulsive forces during swallowing (2). The symptoms produced by lipoma are dysphagia, chest discomfort, sore throat, hiccups, and regurgitation of food. Resection is the treatment of choice to avoid asphyxiation due to airway obstruction when the lesion grows (3).
Y. Kise, H. Makuuchi, H. Shimada, K. Mizutani, O. Chino,

T. Mitomi

Second Dept. of Surgery, Faculty of Medicine, Tokai University, Kanagawa, Japan

\section{References}

1. Mayo CW, Pagutalunan PJG, Brown DJ. Lipoma of the alimentary tract. Surgery $1963 ; 53: 593-603$.

2. Avezzano EA, Fleischer DE, Merida MA, et al. Giant fibrovascular polyps of the esophagus. Am J Gastroenterol $1990 ; 85: 299-302$.

3. Allen MS, Talbot WH. Sudden death due to regurgitation of a pedunculated esophageal lipoma. J Thorac Cardiovasc Surg 1967; 54: 756-8.

Corresponding Author

Y. Kise, M.D.

Second Dept. of Surgery

Faculty of Medicine

Tokai University

Bohseidai, Isehara, 259-11

Kanagawa

Japan

Fax: $+81-463956491$
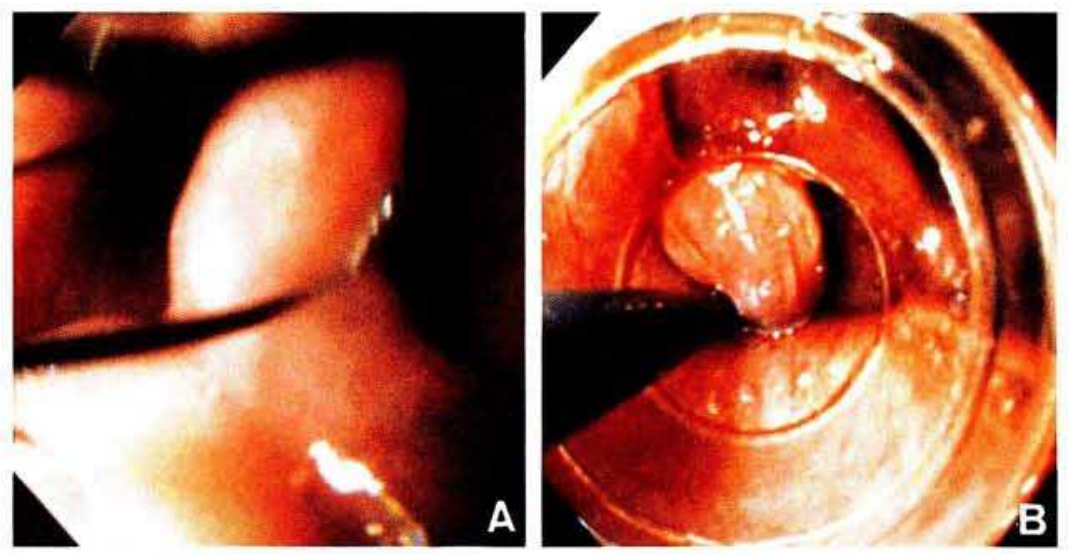

Figure 1: Endoscopic resection of two pedunculated polyps. The larger polyp, $70 \mathrm{~mm}$ in size, was trapped by the snare (a), pulled into the endoscopic mucosal resection tube (b) and resected by coagulation. The remaining smaller polyp was by coagulated at the stalk (c), and aspirated into the resection tube. $\mathbf{d}$ The resected double pedunculated polyp, arranged in its original configuration on the same stalk.
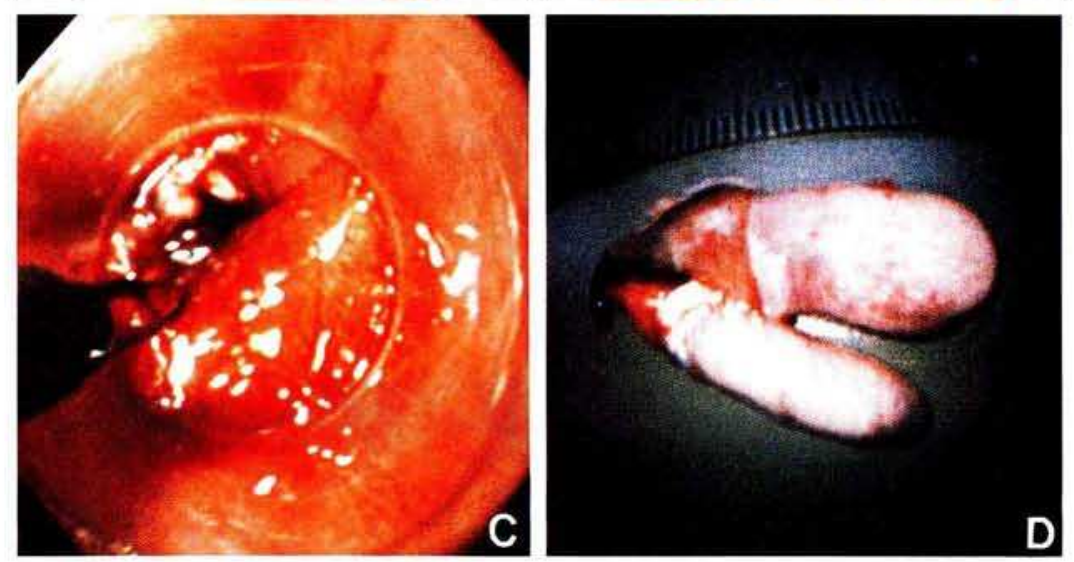